The Influence of Alcohol and of Anaesthetics. ${ }^{19}$

Alcohol acts upon the vasomotor system and also upon the nervous control of the production of heat. The dilatation of the cutaneous vessels, the increased perspiration and the cooling thereby produced are weil known. The temperature of the subject may be lowered although he himself feels warmer; this is due to the warm blood which flushes the cutaneous nerves where the sensations of temperature arise. In large doses alcohol paralyses the nervous control of temperature. The man who is " dead drunk" resembles a coldblooded animal; exposure to cold produces not an increase but a decrease in combustion and his temperature steadily falls. The lowest temperatures recorded in men, who have recovered, appear in drunkards who have been exposed to cold.

Anaesthetics rapidly paralyse the nervous regulation of temperature. The disturbance in temperature, be it a fall or a rise, which is seen after many surgical operations, appears to be largely due to this cause. The convenient explanation of "shock" needs further definition. The anaesthetized patient cannot regulate his temperature. The importance of warm surroundings to a patient who is deeply under an anaesthetic during a long operation is generally recognized. Such patients require warmth ; an anaesthetic in the case of warm-blooded animals quickly reduces the combustion of the body to one-half its normal value; the vital resistance and the power of accommodation are concomitantly reduced. Warmth will increase, cold, even moderate cold, will diminish the combustion.

From a physiological point of view anaesthesia would appear to be often too deep and prolonged. Pain is beneficent in numerous cases; it is a natural safeguard, and brings about appropriate responses to sensations which are too often quenched by an anaesthetic. A drug which will so profoundly disturb the nervous control of combustion can never be considered harmless. The rapid recovery of animals and savages from serious wounds is generally attributed to a greater resistance; but the question can be fairly asked whether the smaller resistance of the civilized man is not further diminished, and often seriously diminished, by deep and prolonged anaesthesia? The patient dies-not, it is said, from the anaesthetic, not from the operation, which was quite successful, but from "shock"-he does not rally. May not this absence of a rally largely depend upon the fact that the combustion of the body, one of the most characteristic signs of life, has been so greatly diminished and for a time, at least, has been removed from the control of the nervous system? It is impossible by means of an anaesthetic to influence the nervous system alone; the body works as a unit, and as such is affected by abnormal conditions.

The Limits of Bodily Temperature compatible with LIFE. ${ }^{19}$

Under pathological conditions the temperature of man shows a range of about $22^{\circ} \mathrm{C}$. (approximately $39^{\circ} \mathrm{F}$.), from $24^{\circ}\left(75.2^{\circ} \mathrm{F}\right.$ ) to $46^{\circ}$ (114.8 $8^{\circ}$ F.). Higher and lower temperatures have been observed in moribund patients; here, however, only well-authenticated cases, in which recovery took place, need be considered. Several observers have recorded rectal temperatures as low as $24^{\circ}\left(75.2^{\circ} \mathrm{F}\right.$.) in drunkards who have been exposed to cold for several hours; the patients were unconscious, but under careful treatment recovered in two or three days. Low temperatures have also been observed in chronic cases of insanity, and have persisted for several weeks.

The cases of hyperpyrexia scattered throughout medical literature are exceedingly numerous. Some of the observations appear to be unreliable, owing to defects in the thermometer or to fraud on the part of the patient. The range above the normal temperature is less extensive than that below, and a very high temperature is rapidly followed by death, whereas a very low temperature is compatible with life for a relatively long period. This would be expected on general physiological grounds, for some mammals have, under the natural conditions of hibernation, a temperature only five or six degrees abnve the freezing point.

The highest records in patients who have recovered appear to be $45^{\circ}$ to $46^{\circ}$ ( $113^{\circ}$ to $114.8^{\circ} \mathrm{F}$.), but in these cases the high temperature appears to have been maintained for a very short time.

1 Edwards, De l'Influence des Agens Physiques sur la Vie, Paris, I824. 2 Pembrey, Journ. Physiol, Cambridge and London, x895, vol. xviii, p. 363. Zeit. f. Biol., München, 1888, Bd. xxiv, s. ${ }^{23}$. 3 Babák, Arch. f. d. ges.
Physiol., Bonn, 1902, Bd. 89, 8. 154. ${ }^{6}$ Sutherland, Proc. Roy. Soc., Victoria, 1897, vol. ix, p. 57. ${ }_{7}$ Martin, Fhil. Trans., London, 1902, vol. cxcv B, p. x Lorain, De la Temperature du Corps Humain, Paris, 1877, Tome i, p. 1 Pembrey, article Animal Heat, Textbook of Physivlogy, edited by Schäfer, Edinburgh and London, 1898 , vol. i, p. 824 . Pembrey and Nicol, Journ. Physiol., Cambridge and London, 1808, vol. xxiii, p. 386, see also references 16 and 18 . 10 Stephen Hales, Statical Bssays, London, 1731, second edition vol. if p. 59. 11 Pembrey and Nicol, loc. cit.; ; see also 16 . 12 Ringer and Stuart, Proc. Roy. Soc., London, 1877, vol. xxvi, p. 186 . 13 The references to these authorities are given in Animal Heat, loc. cit. 14 Sutherland Simpson. Proc. Phys. Soc., Journ. Physiol., Cambridge and London, 1902, vol. Xxvili, p. Xxi. ${ }^{15}$ Eyre, ibid., 1900, vol. XXv, p. Xxiv. ${ }^{16}$ Pembrey, Arkle, Bolus, and Lecky, Guy's Hospital Reports, London, rgoz, vol. lvii, p. 283. 17 Pembrey, 1bid., p. 26r. 18 Burton-Fanning and Gurney Champion. Lancet, London, March' $28 \mathrm{th}$, $1902 .{ }^{19}$ Numerous references are given in Animal Heat, loc. cit.

\section{THE CAUSES AND TREATMENT OF CHRONIC RHEUMATISM.}

BY RALPH STOCKMAN, M.D., Professor of Materia Medica and Therapeutics, Glasgow University
Physician, Western Infirmary of Glasgow.

Ac0TE rheumatism is an acute microbic infection, running a course of variable duration when untreated, and usually presenting certain well-defined symptoms which render its diagnosis an easy matter. One attack predisposes to others. Those cases which we are accustomed to call "subacute rheumatism" are really milder cases of the same disease, and no hard and fast line of distinction can be drawn. A case of acute rheumatism may be unusually prolonged, but never becomes chronic in the true sense of the term. That is to say, it never becomes chronic any more than enteric fever or diphtheria, becomes chronic. These diseases may leave sequelae in the form of bowel lesions or peripheral neuritis, respectively, but such sequelae are not designated chronic enteric fever, or chronic diphtheria. In the same way acute rheumatism may cause fibrous thickening of the valves of the heart, or fibrous indurations of the aponeuroses, fasciae, ligaments, and nerve sheaths, but these are results of the original disease and not an indefinite continuation of it.

Such indurations of the fibrous tissue give rise to pains referred to the muscles, joints, and nerves; but these symptoms, and the lesions causing them, cannot properly be re. garded as the chronic stage of acute rheumatism. more especially as acute rheumatism is not the only condition which precedes them and is responsible for their presence. Nevertheless, the name chronic rheumatism has been so long applied to chronic painful conditions of the muscles and joints that its retention is now a matter of convenience. In the popular mind, and, to some extent, in the medical mind, the name has been long associated, specially and almost exclusively, with affections of the joints; and formerly, when so many separate and quite distinct articular lesions were classed together as "rheumatic." this idea was, to a large extent, justified. Gradually, however, the meaning of the term has become much narrowed by more accurate diagnosis, and we now distinguish rheumatoid arthritis, morbus coxae senilis, coxa vara, pulmonary osteoarthropathy, Haygarth's nodosities, septic and gonorrhoeal arthritis, and other diseases and affections implicating the joints, as things quite distinct from each other and from chronic rheumatism. It is also now recognized that the articular structures proper-cartilage, synovial membrane, bone - are not primarily affected in chronic rheumatism, but that the parts implicated are the fibrous ligaments of the joints, and more especially all the fibrous tissues of the muscles and bones. In our textbooks the condition is described as chronic rheumatism, muscular rheumatism mascular and tendinous rheumatism, myalgia, rheumatic myositis, pain being assigned the most prominent place as a symptom and damp cold as an exciting cause. Its original causation is variously stated as a rheumatic affection, as a special infection, as a diathesis, as a neuralgia, as a manifestation of gout, and as a muscle pain from imperfect nutrition. The same indefiniteness characterizes the accounts given of its pathology. Some authors hold that there are no morbid anatomical changes, others consider it a neuralgia, or an active hyperaemia of the muscles, or of their fibrous sheaths, while only a few describe definite fibrous changes and thickenings in the connective tissues. Speaking in general terms, the treatment recommended is regarded as palliative rather than curative, and no great hope of complete and ultimate relief is held out. A consideration of its pathology and experience of the results of properly-lirected and persevering treatment haveled me, how- 
ever, to take a more hopeful view of the prospects of sufferers from chronic rheumatism.

Pathology.

The essential pathological changes are confined to the white fibrous tissue, and as this forms so large a part of the locomotory apparatus of the body, we accordingly find that chronic rheumatism affects specially the aponeuroses, tendons, fibrous septa, sheaths of muscles and nerves, periosteum, and the fibrous structures of joints. The lesion consists in inflammation and hyperplasia of the connective tissue in patches, and this condition may be widely spread over the body, or may be confined to a certain area of it. Serofibrinous exudation with proliferation of the connective tissue takes place, probably as the result of irritation from microbes or a toxin. This may be wholly or partially reabsorbed, or may organize and form permanent fibrous swellings and indurations. On microscopic examination they are seen to consist of proliferating fibrous tissue and exudation (when recent), or (when older) chiefly of dense fibrous tissue. They are well supplied with blood vessels, and no leucocytes congregate about them, as happens in so many inflammations. Once these fibrous swellings form, they are liable to become swollen and painful under the influence of cold, damp, over-exertion, indigestion, and other causes, and in this manner chronic rheumatism is established. The fibrous indurations are frequently defined and circumscribed, varying in size from a small shot or split pea to an almond or half a walnut, or a whole aponeurosis, as in the lumbar region or fascia lata, may bs thickened, imparting to the skin over it a hard, inelastic feel. Very frequently the thickening takes the form of a strand or cord ranning through the fascia, or of small periosteal nodules, or of swelling on a nerve sheath. Local injuries, such as sprains, rupture of muscle fibres, dislocations, and so on, often give rise to similar indurations of the fibrous tissue, and these often cause local rheumatic symptoms, sometimes very troublesome and intractable to treatment.

If these swellings are at all superficial they can be very distinctly felt, and are usually painful on pressure. The commonest situations for them are in the lumbar aponeurosis, calves, fascia lata and tendinous expansions of the thigh muscles, the trapezius, deltoid, inner border of biceps, intercostal muscles, the glutei, and the soles of the feet. The fibrous tissue of the neck of the bladder, of the pharynx, behind the sternum, and all along the spinal column and in the joints may also be affected. When these local indurations swell up-as they do from various causes-there follows local tension, with pressure on the filaments of sensory nerves. This gives rise to almost continual aching, pain, and a sense of muscular fatigue. Sudden miscular movement, by increasing the tension or exerting pressure on the swoilen tissue, often greatly aggravates the pain or causes it to slioot excruciatingly. Owing to the implication of sensory nerves the aching and pain may often radiate over a wide area; hence also the numbness, tingling, and prinkling which are common symptoms of chronic rheumatism.

\section{ETIOLOGY.}

As regards the etiology of chronic rheumatism, it is necessary to differentiate between (I) the original causes of the fibrous indurations and (2) the causes of the exacerbations once the fibrous thickenings have become fully established, and the patient suffers habitually from his rheumatism.

In adults, as in children, it is comparatively common for fibrous thickenings to occur as accompaniments or sequelae of acute rheumatism. They may disappear, or may remain after all symptoms of the original acute attack have gone, they ache under slight exposure to cold, are painful on pressure, and often very intractable to treatment. True influenza is another cause, and slight febrile attacks, with pain and aching in the muscles and bones (often described as an "influenza cold" or a "rheumatic cold"), also bring on these fibrous thickenings. Sore throat seems to be another cause, and, as previously mentioned, local injuries to joints and muscles may have the same effect. In a certain number of cases no cause can be assigned beyond frequent exposure to cold and wet, or to extremes of heat and cold, accompanied often by hard muscular work. Chronic rheumatism is said to be a disease of maturer years, but this is hardly correct. A certain degree of it constitutes "the stiffness of age," but it is very common in adolescents and in early middle life. It is therefore not a diathesis but a local affection of the fibrous tissues, and it apparently results from several preceding causes.
Once the fibrous indurations are established, cold, damp, draughts, wet clothing, weather changes, unusual or violent muscular exercise, intestinal indigestion, and other causes have a very marked influence on their condition. Under the influ. ence of these exciting causes the fibrous tissue formations become swollen and more tense, and give rise to pain and aching, which disappear very slowly or nay suffer exacerbation from renewed exposure. Hence in some cases the patient is never quite free from muscular aching, and may have neuralgia in addition.

\section{Symptomatologr.}

The symptoms of chronic rheumatism are so well known that I need only refer to them very briefly. During an exacerbation aching and pain referred to the muscles, fasciae, tendons, and joints torment the patient, there is a feeling of fatigue and tiredness, and often marked sleepiness. When the more acute stage passes off, it is succeeded by intermittent stiffness and aching, especially felt in bed in the morning, or after resting, or remaining for a time in one position.' In certain patients it may recur again and again in the same part (lumbago, stiff-neck), or it may be widely distributed over the body. The stiffness and aching usually wear off on active movement or exertion, but recur again very soon. Any sudden movement which compresses a swollen induration may cause very severe and crippling pain (as in lumbago), but apart from this the affected muscles are easily tired and often ache intolerably for days after even moderately severe exertion. Some of the joints and nerves may be more or less painfu], and the digestion is not infrequently out of order. The general health may be mediocre or fairly good, but if there is much continuous neuralgic pain the patient may become thin, peevish, and neurasthenic.

Firm gentle pressure over the skin, which it is best to smear with liquid paraffin or some oleaginous material, reveals the presence of the indurations, nodules, or thickenings, which have been previously described. These are painful or tender when pressed upon with some little force, and become less painful after a few minutes of gentle effleurage.

Treatment.

During an acute exacerbation, when the indurations swell up and cause pain and aching, relief may be given by hot baths, massage, phenacetin, Dover's powder, sodium salicylate, the local application of methyl salicylate and similar measures. But the relief thus afforded is only temporary, and often in a few hours, or as soon as treatment is stopped, the pains return to continue for days. weeks, or indefinitely, and the patient remains as before, liable to renewed attacks on every exposure to cold, wet, or fatigue.

To obtain permanent cure and complete relief from the recurrent attacks, the fibrous indurations must be completely dispersed, and in all but quite recent cases this is always a more or less tedious and troublesome procedure. The only means which I have found of any special and definite value in this respect are massage and exercises, the faradic current, and the injection of solution of chromic acid into any of the fibrous ind urations which are sufficiently large and defined to allow of this being done. Of the three, massage is the most efficacious.

General massage is of no use. It must be specially directed to any nodules or thickenings which can be felt. At first they are often too tender to be rnbbed with much pressure, but gradually they become more callous and more fibrous, and may then be more vigorously treated. A good deal of experience and skill is required during the early treatment, but after they begin to shrink in size, the knuckles and fists may be used for rubbing, and ultimately they disappear. The massage should be carried out daily, 10 or 15 minutes being devoted to each part. To obtain satisfactory cure the dispersion of all the indurations must be complete, otherwise relapses occur and are a source of much disappointment. The length of time required to do this varies very much. Recent soft swellings may disappear in two or three weeks, but when the indurations are old and widely spread three to six or twelve months may be required.

Exercises calculated to stretch the aponeuroses and muscles involved are of value in hastening and completing the cure. A stick, dumb-bells, Indian clubs, Sandow's \& xerciser, may all be called into requisition to provide suitable movements.

The faradic current should be applied over each region for 
five to ten minutes daily. It has some effect in causing shrinkage of the swollen fibrous tissue.

\section{Injection of Chromic Acid.}

This method is only possible where the nodule is sharply detined and can be penetrated accurately by the hypodermic needle. Superficial nodules should never be treated in this way, as the solution is apt to damage the skin and cause 8 phlegmon. Ten minims or less of a 1 per cent. solution in water may be given. It may cause some aching, but if the nodule has been accurately injected, shrinking, with great relief to the rheumatic pain, follows.

\section{Drugs.}

Where intestinal indigestion is present, and especially in lumbago, a course of mild purging (grey powder, compound rhubarb powder, salines) is advisable. As regards specific remedies, it cannot be said that any are known which cause absorption of the fibrous indurations. In quite recent cases I have seen potassium iodide give relief, but in regularly chronic cases any benefit is not very apparent. Salicylic compounds lessen. pain during the exacerbations. Their action is not curative, however, as they cannot be expected to remove hard fibrous tissue. The same is true of phenacetin, phenazone, quinine, and all similar cornpounds. Alkalies, ammonium chloride, colchicum, guaiacum, actaea racemosa do no good. Iodine and local blistering are helpful, especially over joints or nerves.

\section{Spa Treatment.}

Recent cases, where the fibrous thickenings are in the early stage and still plastic, may be cured by a course of hydrotherapy, but inveterate cases only obtain temporary relief from their sufferings. The drinking, bathing, and general massage promote absorption of the serous exudation in the fibrous tissue. and possibly some shrinking. This usually gives for a time complete relief to the pain, aching, and stiffness of chronic cases, so that the patient feels much more happy and energetic. The indurations still remain, however, and are apt to swell and give trouble under the influence of exciting causes. The regular purgation obtained at Harrogate by the sulphur water improves intestinal digestion and does much good in certain cases.

\section{Diet.}

The broad rule is to avoid gastro-intestinal fermentation and the consequent absorption of irritant products from the bowel. Indigestion certainly causes aching in many rheumatic subjects, and the best way to avoid it is to eat plainly but sufficiently of an ordinary mixed diet. Any articles which are well and easily digested by the individual may be allowed.

\section{Climate.}

Residence in a dry stimulating climate often brings about spontaneous cure. A damp atmosphere and a seaside climate increase the symptoms, and seem to favour the conditions which give rise to chronic rheumatism.

\section{Surgical Treatment.}

Certain nodules after prolonged massage remain very hard, and refuse to be dispersed. If they cause pain and aching, they can be removed surgically. Removal gives complete relief. It is sometimes not an easy operation, as the small mass of fibrous tissue often lies deep, and may be difficult to find.

In recent cases the prognosis is good, and even in cases of some years' standing complete, or almost complete, recovery is assured, if the treatment be persevered with. It requires considerable resolution and determination on the part of the patient, as it takes time and trouble, relapses are common, and he is apt to get discouraged. In severe cases, where there is marked and widespread induration, and the patient is very stiff and crippled, recovery is hopeless; but by stretching, massage, and manipulations, more freedom of movement may be obtained. When the subcutaneous tissue is thickened and brawny, treatment is very tedious, and recovery usually only partial. The same is true of joints. which have been long affected.

Prophylaxis.

After rheumatic fever, influenza. muscular chills, violent exertion, sprains, dislocations, and other conditions which bring on indurations of the fibrous tissue, the patient should be treated, and preferably perhaps at a spa, by massage, elec- tricity, and bathing. After being cured of chronic rheumatism, a somewhat " hardening" mode of life should be adopted, with plenty of outdoor exercise. Any relapse should be at once treated.

\section{A CAST OF SCURVY IN AN INFANT FED ON MUENICIPAL "HUMANIZED" STERILIZED MILK.}

BX' HENRY ABHBY; M.D., F.R.C.P.,

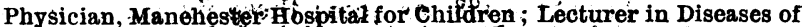
ohllaren, Owehs Colfege.

In a leading article in the Bririsa Menical Journal of September 26 th, 1903, p. 746 , reference was made to municipal milk supplies for infants, and a note of warning sounded as to their limitations and dangers: and at the annual 'meeting of the Association both Dr. T. D. Lister and Dr. E. Cautley called attention to the risks attending the haphazard distribution of municipal "humanized" sterilized milk."

As illustrating these remarks I am tempted to publish a case which came under my observation a short time ago. The parents were a strong and healthy couple who brought me their first infant, ro months old. The father belonged to the higher artisan class, being an overlooker in a mill and earning good wages. The history was that the infant had been born healthy, and was nursed by its mother till it was six weeks old, but as at this time she was not satisfied with its progress, she weaned it, substituting "humanized" sterilized milk obtained from a municipal milk dépôt. The parents appear to have obtained two days' supply at a time, the milk being supplied in eight bottles in a crate! The milk was stated to be white and sweet, but there often was butter oil floating on the top after the milk was warmed. They had used this milk exclusively till the present time, apparently of the original strength, but had increased the amount, and had added some baked flour. The infant did fairly well till he was about. 8 months old. He then began to cry when handled, and kept. his legs still as it paralysed, instead of kicking aboutas he used to do. When I gaw him at the age of ro months the gums were swollen and purplish around four incisor teeth which had been cut, the roots of the finger nails were injected, both legs beneath the knees were much swollen, immobile, tender and shing; there was tenderness of the bones of the arms. The infant was poorly nourished; there was some enlargement of the epiphy\&es of the forearms.

The case did not differ in any way from the cases of scurvy so often seen from tine prolonged use of preserved foods, but. the fact that the milk which had given rise to the scurvy had heen obtained from a municipal dèpot supplies food for reflection in several ways.

In the first place I should like to say that for every typical case of scurvy met with in either private or hospital practice at least half-a-dozen will be seen who have been fed on preserved foods which exhibit indefinite symptoms of scurvy. which may be called "para-scorbutic." The tenderness of the bones may be entirely absent, but there is anaemia, loss of flesh, distaste for food, sometimes diarrhoea of a dysenteric type, more rarely hapmaturia, a fine zone of pinkness in the gums around the teeth and perhaps a similar zone of pinkness at the root of the finger nails. In some cases there are herpetic-like rashes. In such cases improvement at once follows a change of food such as a milk-whey mixture and orange juice. I mention this because I feel sure the amount of mischief done by preserved foods is not to be measured by an odd case of typical scurvy.

A municipal supply of "humanized" milk cannot be provided except at considerable loss to the ratepayers; it cannot possibly be made to pay its way, assuming that fresh milk and cream of good quality are obtained from suitably-foddered and clean cows, and bottles, teats, and crates are providrd. There is also the rent of the dépôt, the sterilizing apparatus, and the labour to be reckoned with. . A charge of 3d. a day, or rs. $6 \mathrm{~d}$. a week, cannot cover the cost. There is certainly a risk that the class who usé the dépôt belong to the bettercircumstanced artizan class rather than the poorest class who get their milk by the pennyworth. It is difficult to know how this is to be prevented, but it is certain that it is among the latter class that the infant mortality is the highest, and that it is they who need the greatest looking after.

I wish all the municipal authorities would get rid of the word "humanized," and substitute "modified" or any other word in the dictionary they like. Municipal milk is sold with 